\title{
COLLEGE ACHIEVEMENT AND ATTAINMENT GAPS: EVIDENCE FROM WEST POINT CADETS
}

\author{
Dario Cestau \\ Dennis Epple \\ Richard Romano \\ Holger Sieg \\ Carl Wojtaszek \\ Working Paper 27162 \\ http://www.nber.org/papers/w27162
NATIONAL BUREAU OF ECONOMIC RESEARCH
1050 Massachusetts Avenue
Cambridge, MA 02138
May 2020

Financial support for this project was provided by the NSF grant SES-1658746. The views and findings expressed herein are those of the authors and do not purport to reflect the position of the U.S. Military Academy, the Department of the Army, the Department of Defense, or the National Bureau of Economic Research.

NBER working papers are circulated for discussion and comment purposes. They have not been peer-reviewed or been subject to the review by the NBER Board of Directors that accompanies official NBER publications.

(C) 2020 by Dario Cestau, Dennis N. Epple, Richard Romano, Holger Sieg, and Carl Wojtaszek. All rights reserved. Short sections of text, not to exceed two paragraphs, may be quoted without explicit permission provided that full credit, including $\odot$ notice, is given to the source. 
College Achievement and Attainment Gaps: Evidence from West Point Cadets

Dario Cestau, Dennis Epple, Richard Romano, Holger Sieg, and Carl Wojtaszek

NBER Working Paper No. 27162

May 2020

JEL No. I2,J15,J24

\begin{abstract}
$\underline{\text { ABSTRACT }}$
Assessing the effectiveness of education by race and gender is as difficult as it is important. We investigate this question utilizing data for eleven cohorts at West Point, a distinguished military academy and highly ranked liberal arts college. Employing matching using entry scores on three comprehensive measures, we obtain exceptional matches of score distributions for black and matched white students. We find black students have lower graduating achievement scores than matched white students, but comparable rates of graduation, retention in the Army after graduation, and early promotion. Hispanic-white comparisons reveal no differences. Female-male comparisons reveal women have lower attainment and retention rates.
\end{abstract}

\section{Dario Cestau}

IE Business School

Madrid

Spain

Dario.Cestau@ie.edu

Dennis Epple

Carnegie Mellon University

Tepper School of Business

Room 4126

Pittsburgh, PA 15213

and NBER

epple@cmu.edu

Richard Romano

University of Florida

Department of Economics

PO Box 117140

Gainesville, FL 32611

romanor@ufl.edu

\author{
Holger Sieg \\ Department of Economics \\ University of Pennsylvania \\ 3718 Locust Walk \\ Philadelphia, PA 19104 \\ and NBER \\ holgers@econ.upenn.edu \\ Carl Wojtaszek \\ United States Military Academy \\ Department of Social Sciences, \\ West Point \\ carl.wojtaszek@westpoint.edu
}




\section{Introduction}

In Gratz v Bollinger, an amicus brief in support of the diversity policies of the University of Michigan was submitted to the U.S. Supreme Court by an exceptionally distinguished group of military officers. They were unequivocal: "Based on decades of experience, amici have concluded that a highly qualified, racially diverse officer corps educated and trained to command our nation's racially diverse enlisted ranks is essential to the military's ability to fulfill its principal mission to provide national security." This position was buttressed by their review of the history of troubled race relations in the military and the adverse consequences of a "...chasm between the racial composition of the officer corps and the enlisted personnel ..." These officers emphasized the importance of bringing minority representation in the officer corps into balance with minority representation in enlisted ranks 1 With this backdrop, they argued forcefully for policies that increased diversity in the service academies and ROTC. In closing their brief, these officers emphasized that "... the military must be selective in admissions for training and education for the officer corps, and it must train and educate a highly qualified, racially diverse officer corps in a racially diverse educational setting." ${ }^{2}$

Cast in the context of their own institutions, the above views would resonate broadly among leaders in higher education. All institutions of higher education confront a common set of challenges: assessing the capabilities of applicants and selecting those best suited to the mission of the institution, fostering diversity, inculcating knowledge, and placing graduates in productive careers. Given the range of skills required for a military officer to be effective, these challenges are arguably more daunting for service academies than for other academic institutions. Because of clarity about their mission and its importance to the nation, service academies are also arguably ahead of their civilian counterparts in focusing on assessment of the extent to which they are accomplishing their objectives. Civilian institutions are,

\footnotetext{
${ }^{1}$ This continues to be a central concern; the proportion of officers who are African American is one fourth as large as the proportion in the enlisted ranks.

${ }^{2}$ In reading the majority opinion in the recent U.S. Supreme Court decision in Fisher v University of Texas, one cannot help but be struck by the extent to which the views expressed by these officers are reflected in the Court's rationale for its decision.
} 
however, increasingly focused on assessment of effectiveness. This focus is being stimulated by two forces. One is stiffening public resistance to the rapid rise in the cost of education. The other is increasing concern by governments at all levels about whether colleges are making effective use of funds from public programs that are designed to help advance the fortunes of disadvantaged members of the population. Because of the intense controversy that accompanies affirmative action, it is also of much interest to investigate education and outcomes in a setting in which affirmative action is not practiced.

The systematic evaluation needed by policy makers requires a clear understanding of the mission of a college coupled with data on qualifications of applicants, measures of academic performance, measures of success of placement, and measures of career accomplishments. On all of these dimensions, the U.S. Military Academy at West Point provides an ideal research setting. Several features of the West Point setting facilitate this analysis. First, there is substantial commonality in courses that students take. All take a common core curriculum during the first two years of study. In addition, each student is required to have a minor in engineering. This results in commonality in types of courses taken in the third and fourth years at the college. Second, a great deal of effort at West Point is devoted to uniformity of delivery of instruction, leaving limited scope for unobserved differences in the quality of instruction to drive observed achievement differences. Third, students attend full time and, hence, there are no complications associated with evaluation of part-time students. Fourth, West Point measures skill acquisition in three distinct areas: academic, leadership, and physical fitness. Weights on these three areas in determining admission are 60\%, $30 \%$ and 10\% respectively. West Point uses comprehensive standardized examinations to measure skills in these areas for both applicants and cadets. This rich body of data permits us to measure development of these skills over the course of a student's education. Fifth, all graduates are required to serve at least five years in the military. Hence, all graduates have the same employer for at least five years following graduation. Sixth, we have panel data for 11 cohorts. As a result, we have large enough samples to permit us to investigate differences 
by race in college achievement and careers in the military. In addition, the number of white women cadets is sufficiently large to permit us to study gender differences in outcomes among white cadets.

It might be objected that West Point is sufficiently different from other US colleges that research findings drawn from West Point might not transfer to other institutions. While there is some merit in this concern, West Point is similar to other undergraduate colleges in many ways. It is a four-year coeducational undergraduate institution offering 36 academic majors. Students take 40 courses of which 32 are on subjects typical of other undergraduate colleges. The remaining 8 focus on development of military knowledge and skills. Implications drawn from West Point are likely to apply most directly to technically oriented undergraduate colleges. Of the 36 academic majors at West Point, 23 are in STEM areas, and all graduates of West Point receive a Bachelor of Science degree. In USNews rankings, West Point is ranked number 21 among National Liberal Arts Colleges and number 2 among Top Public Colleges ${ }^{3}$

As emphasized in the quotation provided at the beginning of this introduction, effectiveness of the U.S. Army requires an officer corps that reflects the composition of its enlisted force. This in turn highlights the need for the Army to educate and retain a significant fraction of minority officers. Given that minority students come from disadvantaged educational backgrounds, they are likely to be farther from reaching their potential than majority students when starting college. Hence, not surprisingly, minority students enter the academy with, on average, lower academic and leadership skills. The central objective of our analysis is to assess whether attainment, achievement, and career outcomes of minority students are equivalent to those of majority students with comparable measured entry capabilities. While our primary focus is on black-white comparisons, we study Hispanic-white gaps as well as gender gaps among white cadets.

Our data are for the 11 cohorts of cadets that enrolled at West Point between 1998 and 2008. This sample has 9,892 white cadets, 840 black cadets, and 771 Hispanic cadets, 1,450

\footnotetext{
${ }^{3}$ The rankings are published at https://www.usnews.com/best-colleges/west-point-2893/overall-rankings.
} 
white female cadets, 191 black female cadets, and 124 Hispanic female cadets. Our descriptive analysis documents the differences by race in the initial skill distribution among the entering cohorts of cadets at the academy. In particular, we find, as expected, that enrolling black and Hispanic students tend to have significantly lower mean academic scores than white students 4

The key challenge encountered in the empirical analysis is then to account for these initial differences in college readiness skills when assessing the impact of West Point education on achievement, attainment, and career outcomes. Because of challenges in determining an appropriate functional form, regression can be problematic in attempting to identify causal relationships. Hence, we primarily rely on matching estimators in our empirical analysis. A key advantage of matching estimators is that they typically do not require specifying the functional form of the outcome equation and are, therefore, less susceptible to misspecification bias along that dimension (Rubin, 1973,1974). Matching by race has been used in economic research, discussed in our literature review below, and in medical research, for example in comparing black-white breast cancer survival rates (Silber, Rosenbaum, Clark, Giantonio, Ross, Teng, Wang, Niknam, Ludwig, Wang, Even-Shoshan, and Fox, 2013) and black-white colon cancer survival rates (Silber, et.al., 2014).

A primary goal of our analysis is to assess the extent to which the extensive performance and experience metrics available to West Point at the time of admission are equally successful in predicting outcomes by race and by gender. Therefore, we do not utilize family background measures in our matching analysis. We match on the three metrics that, in combination, determination admission to West Point: academic preparation, leadership skills, and physical fitness. These are denoted respectively College Entrance Examination Rank (CEER), Community Leader Score (CLS), and Physical Aptitude Exam (PAE). Each of these measures is precisely defined and consistently applied both across applicants in a cohort and across cohorts. As additional matching variables, we use indicators of prior active military service,

\footnotetext{
${ }^{4}$ There are no significant initial differences by gender.
} 
attendance at the West Point preparatory school (USMAPS), and the product of the two $5^{5}$

As discussed in detail by Diamond and Sekhon (2013) and Imbens (2014), matching is not straightforward when matching on multiple dimensions. First, matching requires that there be a sufficiently large overlap in the distribution of covariates of the two types being matched, otherwise the "region of common support" assumption would be violated. Fortunately, our sample is quite large, and, more importantly, the empirical distributions of each of the three main covariates of interest has a common support. Hence, the common-support assumption is well satisfied by our data. In matching, the objective is to achieve full covariate balance. For example, in comparison of outcomes for black and white students, our objective is to choose a matched white sample such that the distribution of covariates used in matching is the same as the distribution for the black students ${ }^{6}$ Finding a match that achieves the best covariance balance obtainable in a given application requires use of an algorithm that goes beyond matching of a propensity score. Several algorithms have been developed. As we show below, we obtained exceedingly good matches using the matching method of Abadie and Imbens (2006) implemented in the "genetic" algorithm in the R package named MatchIt. 7 Match quality can be assessed based on standard difference-in-means tests between matched pairs. Assessing covariate balance for continuous variables entails, in addition, comparisons of the distributions of the matching variables between the two groups being matched. For this, QQ plots are particularly useful. Using these criteria, we find that the generic matching algorithm delivers very close matches for all matching variables for all three subsamples of interest (black-white, Hispanic-white, and male-female).

Matching methods by themselves are not methods of estimation. Every use of matching in the literature involves an estimation step following the matching procedure. We follow the common approach and use simple regressions in the second stage of the analysis. Using the

\footnotetext{
${ }^{5}$ USMAPS is the acronym for US Military Academy Preparatory School.

${ }^{6}$ Rosenbaum and Rubin (1983) establish that a correctly specified propensity score will asymptotically achieve covariate balance. The correct propensity score is, of course, unknown. An incorrectly specified propensity score need not achieve covariate balance, and the attendant results of the analysis may then be invalid.

${ }^{7}$ See Ho, Imai, King, and Stuart $(2007,2011)$ for detailed discussion.
} 
black-white matched sample, we regress the outcomes of interest on an indicator for race. We do the same for Hispanic-white and male-female comparisons. All reported regressions coefficients are accompanied by heteroskedasticity-robust standard errors.

We use our matching estimators to investigate several important outcomes. The first outcome of interest is college attainment, measured, by graduation from the academy. This is a meaningful outcome since West Point offers a challenging curriculum and training. The average attrition rate is 21.5 percent during our sample period. We find that there is a small gap of approximately 2 percentage points in graduation rates between in the matched sample of black and white cadets, which is far from being statistically significantly. By comparison, the unconditional gap in graduation rates is more than twice as large and statistically significant. However, our matching analysis suggests that almost all of the difference in unconditional graduation rates is due to differences in college readiness. Once we control for these differences in our matching procedure, there is no evidence for differential attainment among black and white cadets. It also bears emphasis that the absolute graduation rate of black cadets, $75.6 \%$, is very high relative to most comparable undergraduate programs. We also find small, insignificant differences in graduation rates between Hispanic and white cadets in our matched subsamples.

We then turn our attention to measuring differences by race in career outcomes. An important advantage of working with West Point data is that we avoid sorting across different employers that typically occurs when students graduate from college. All graduating students at West Point are required to serve for at least five years in the U.S. Army. We analyze retention beyond 5 years and 8 years as well as early promotion to major, which is a key indicator of success in the Army. We find that black-white and Hispanic-white retention and early promotion gaps are small and insignificant.

We then focus on measuring the college achievement gap using the subsample of cadets that graduate from West Point. We find that, within our matched samples, mean entering qualifications of students who drop out do not differ significantly by race or gender. Hence, 
we compare graduation outcomes without need to adjust for differences in selective attrition. We first utilize the general comprehensive measure of student achievement that West Point uses to rank all graduating students. This ranking is known as the order of merit list (OML). The top student is ranked as one and so on. This ranking is not only prestigious within the U.S. Army, but also determines the order of branch choice among the graduating cohort. Hence, it is a high stakes outcome. Using rank on the OML as a comprehensive measure of college achievement, we find that black students tend to underperform relative to matched white students. In particular, black cadets score 84 ranks higher on the OML than white cadets with comparable backgrounds. To calibrate this value, roughly 1,000 cadets graduate per year. Hence, the OML range is roughly 1 to 1,000 .

As noted above, West Point focuses on three clearly identified separate skills: academic abilities, military leadership, and physical fitness. One of the key advantages of using data from West Point is that we have comprehensive measures on all three dimensions both for incoming cadets as well as for graduating cadets. Our detailed analysis of the different skills reinforces our analysis of our comprehensive achievement measure. We find that black graduates have lower scores than white students on each of the three different skill dimensions. We do not find any significant evidence of Hispanic-white achievement gaps.

The finding of small, insignificant differences in measured career outcomes of matched black and white cadets contrasts with the finding of significant differences in achievement at graduation. We can only speculate as to why, but career outcomes are arguably more important than achievement measures at graduation.

We also compare outcomes by gender among white cadets. Here our main findings are rather different than our findings with respect to race. We find that graduation rates for female cadets are significantly lower than those for matched male counterparts, as are retention rates after 5 years and after 8 years. On average, the qualifications of female cadets who drop out are similar to those of male cadets who drop out. On all performance measures at graduation, female cadets perform equally well as their matched male cadets. These findings 
for outcomes by gender after graduation echo those of Bertrand, Goldin and Katz (2010) for MBA students at a prominent US business school.

From a broader policy perspective, we would like to know what colleges can do to close the racial achievement gaps. A unique feature of West Point is that it is affiliated with its own preparatory school, the US Military Academy Preparatory School, known as USMAPS. An offer of admission to USMAPS may be provided to a West Point applicant who initially lacks the grades or skills necessary to succeed at West Point. This school provides an opportunity for would-be cadets to improve their skills and increase their college readiness. The preparatory school primarily serves minority students, students that are recruited as athletes, and students with prior Army service in the enlisted ranks. Our analysis of the data reveals that cadets who attended West Point, USMAPS significantly improved their academic and leadership skills during that year. We estimate value-added models to assess the effectiveness of attending USMAPS for cadets with different backgrounds. We find that USMAPS improves academic and leadership skills of all race/ethnicity groups and for both male and female students. Academic and leadership gains are smaller for black students than white and Hispanic students. Black students gain somewhat in physical fitness while fitness declines significantly for white and Hispanic students.

The main contributions of our paper are: (i) Using matching estimators to compare outcomes by race and gender in a rigorous, challenging undergraduate STEM program that offers Bachelor of Science degrees in 36 academic majors. (ii) Implementing the matching estimators with comprehensive, standardized measures of performance of students at entry, during the program, at graduation, and subsequent to graduation with sample sizes large enough to yield precise estimates with respect to all of these measures. (iii) Demonstrating that, with preparedness taken into account, attainment and career outcomes do not differ by race, but achievement scores of African American students are lower than their matched white counterparts. (v) Establishing that matched white males and females perform equally well in the college, while also showing that, relative to males, females have lower attainment 
rates and lower rates of retention in the military after completing West Point. (vi) Providing strong evidence of effectiveness of a preparatory program.

The rest of the paper is organized as follows. Section 2 provides a brief literature review. Section 3 introduces our data set and provides some institutional background that is important to understand some of the key variables used in our analysis. Section 4 presents the main results and documents differences in college attainment and achievement. Section 5 takes a look at the role of the preparatory school (USMAPS). Finally, Section 6 discusses the policy implications and offers some conclusions.

\section{Literature Review}

Our paper adds to the expansive literature that has analyzed the black-white achievement, attainment and earnings gaps in the United States. Smith and Welch (1989) published their seminal work on the evolution of black-white inequality during the 20th century. Since that paper, it has been well documented that there have been persistent differences between high school completion rates of white and black students in the United States. Evans, Garthwaite and Moore (2016) report that the gap in high school graduation rates fell by $37 \%$ between 1965 and 1986, decreasing from 15.3 to 9.6 percentage points. Then, this progress stopped. White-black high school graduation rates actually further diverged until 1997, when the gap was 14.4 percentage points. This gap began to narrow again in roughly the year 2000 as US graduation rates increased, particularly for black and Hispanic students (Murnane, 2013; Murnane and Hoffman, 2013).

A similar pattern arises for achievement measured by standardized test scores. Neal (2006) used data from the National Assessment of Educational Progress. He showed that reading and math scores for black students in urban areas fell during the 1980s relative to scores for other youth. Further, although aggregate black-white gaps in achievement continued to shrink for much of the 1980s, there is considerable evidence that overall black-white skill convergence had already stopped by the time Smith and Welch (1989) published their findings. In 2012, 
black-white gaps in NAEP math and reading scores of 13-year olds were virtually the same as in 1990. Assessment of whether this gap has changed awaits results of the NAEP 2019-20. The Achievement gap arises prior to high school. Fryer and Levitt (2004) study the early emergence of the black-white achievement gap, focussing on the first two years of school. They show a substantial initial gap in cognitive skills entering kindergarten that can be fully explained by non-race controls. However, by the end of second grade, the gap increases significantly, their best explanation being school quality differences. Hanushek and Rivkin (2009) show that the black-white achievement gap continues to widen in grades 3 through 8 and that most of this occurs at the upper end of the distribution. They provide evidence that school characteristics, specifically inexperienced teachers and high proportion of black students, can explain some of this divergence. There are also persistent differences in labor market outcomes by race. Card and Krueger (1992) document differences in earnings between black and white workers. Neal and Rick (2014) show that, relative to white men, labor market outcomes among black men are no better now and possibly worse than they were in 1970 . Neal and Johnson (1996) provide evidence using AFQT scores that about 3/4 of the blackwhite wage gap of those in their late 20's can be explained by achievement differences in the mid-teens. Black, Haviland, Sanders, and Taylor (2006) employ a matching estimator to estimate racial wage gaps of college educated individuals. By their estimates, all of the wage gap of so educated Hispanics and blacks not from the south is explained by premarket factors, but most of the gap remains for blacks from the south.

There are a number of hypotheses to explain the earlier black-white convergence in educational outcomes including improved parental education (Cook and Evans, 2000), reduced segregation (Jaynes and Williams, 1989), increased school spending (Boozer, Krueger and Wolkon, 1992), changes in within-school factors for integrated schools (Cook and Evans, 2000), better access to health care (Chay, Guryan and Mazumder, 2009), and parenting practices (Thompson, 2018). Less attention has been given to understanding the long lull in the convergence, and research has struggled to determine why it occurred. Evans, Garthwaite 
and Moore (2017) examine the emergence of crack markets as an explanation for the stalled progress in black high school completion rates. Neal and Rick (2014) argue that the rise in the incarceration rate for black men largely explains why there has been no progress in labor market outcomes during the past decades. Murnane (2013) provides an admirable summary of this body of research as well as discussion of factors that may have resulted in the increase in graduation rates from 2000 to 2010 and the narrowing of the black-white gap during that period.

While our focus is on racial differences, we show that, conditional on graduating, white women perform equally well as their male counterparts at West Point. However, women's graduation rate and military career outcomes do not match those of men. A vast literature has examined male-female achievement, attainment, and wage differences. We mention just a few papers. Regarding achievement, while U.S. females have historically lagged behind males in math, and beginning early in schooling (Fryer and Levitt, 2010), the math gap of college bound students has largely closed, despite more females entering four-year colleges (Goldin, Katz, and Kuzeinko, 2016). In college, females have shied away from STEM majors (though not biology), especially engineering (see e.g., Bettinger and Long, 2005), and persistence to graduation in these majors has lagged men (Griffith, 2010). Griffith provides evidence that the presence of more female STEM graduate students increases persistence, and Bettinger and Long provide evidence that female faculty serve as role models. Regarding earnings of the highly educated, Bertrand, Goldin, and Katz (2010) investigate the dynamics of the gender gap for MBA graduates of the Booth Business School at University of Chicago. While incomes post-graduation begin the same, women's relative earnings drop significantly 5 and 10 years out, with child bearing and husband income being two important predictors. Black, Haviland, Sanders, and Taylor (2008) also study gender wage gaps of the highly educated with a large data set of college graduates that permits use of a matching estimator. They show some matched groups have quite small wage differences (e.g., women with high labor force attachment compared to college-educated men). They also demonstrate that regression 
approaches imply different findings. Carell, Page, and West (2010) study gender differences at the U.S. Air Force Academy. Their focus is on explaining why women at the USAFA are 37 percent less likely than men to major in STEM areas, though, as at West Point, the required curriculum dominates course taking and is STEM oriented. They investigate rolemodel effects. Using random assignment of students to required courses, they show equally prepared women are influenced in choosing STEM majors by having women professors.

West Point is like most highly selective colleges and universities with good STEM programs. Some research in higher education has focused on minority and female participation and graduation in STEM majors. It is well documented that graduation of minorities and females that choose STEM majors is low and, respectively, significantly below that of nonminorities and men. While the proportion of minority students that begin as STEM majors in four-year colleges has actually been somewhat higher than whites: 18.6 percent of blacks and 22.7 percent of Hispanics compared to 18.5 percent of whites in 1995-96 (Anderson and Kim, 2006), the respective percentages that persisted and graduated in a STEM major were $41.8,48.6$, and 69.3 . These persistence values are high relative to those found in other studies, perhaps because of inclusion of non-selective colleges. Griffith (2010) calculates persistence-to-graduation rates in a survey of 28 selective colleges and universities of minorities and females that began a STEM major in 1999 equal to, respectively, 35.8 percent and 36.5 percent. The respective values for non-minorities and males were 46.2 percent and 43.1 percent. Griffith provides evidence that students in schools with higher undergraduate to graduate student ratios are more likely to remain in major, consistent with West Point's undergraduate focus, but graduation rates are much higher at West Point across all sub-groups. Arcidiacono, Aucejo, and Hotz (2016, AAH below) estimate a discrete choice model of school, major, and persistence-to-graduation using late 1990's data from California's UC-system, during a period when affirmative action in admissions was practiced at the top universities in the system (e.g., Berkeley). Throughout the UC-system, persistence to graduation of minority STEM majors was 24.6 percent (within 5 years). Their estimates pre- 
dict this could have been modestly increased by minorities attending attending lower ranked UC schools for those in the bottom two quartiles of prior achievement 8 They predict that minorities in the upper two quartiles of prior achievement would not have have gained by attending a lower ranked school The persistence to graduation in STEM majors of the top quartile minority and non-minority students (on the same scale) in the two highest ranked schools were not drastically different, respectively 52.1 percent and 58.1 percent, but these values dropping to 28.9 percent and 45.1 percent among the third quartile students (Table 4, p. 538). Again, we find much higher persistence at West Point and virtually no difference between matched minorities and non-minorities, while being able to use much more detailed data on prior achievement.

Analyzing changes in achievement and attainment gaps among college students is challenging. Extensive data are required for entering qualifications of students as well as measures of their performance within and beyond college. In addition, the environment being studied must serve a sufficient number of minority students to permit making meaningful comparisons with majority students. While these criteria can potentially be met by assembling data across colleges, challenges then arise in addressing both sorting across colleges and heterogeneity of student choices within and across colleges. In addition, differences in family wealth can impact access to other inputs during the college years, which can also confound the impact of college on achievement and attainment. None of these problems are insurmountable, and, as our literature review shows, much has been learned by analyses of cross-college data. Our approach complements AAH (2016), who model choices head on and use college application sets to control for non-observables among students, following the approach of Dale and Krueger $(2002,2014)$. We add to this body of research by studying attainment and achievement of students by race and gender in a single institution, West Point, with a large database, a diverse body of students, commonality of types of courses across academic measures, extensive measures of entering qualifications of students, and measures of achieve-

\footnotetext{
${ }^{8}$ See Arcidiacono and Lovenheim (2016) for a lucid review of the literature on "mismatch," the hypothesis that less prepared minorities attend too rigorous colleges, e.g., as a result of affirmative action in admissions.
} 
ment, attainment, and post-college outcomes. Moreover, there is limited scope for parental resources or environmental factors such as drug use to impact performance. 9

Finally, our paper is related to a research that has studied educational practices and outcomes at the USMA. Lyle $(2007,2009)$ estimates the impact of peer effects and role model effects on human capital accumulation, exploiting random assignments of cadets to social groups at the USMA. Lyle and Smith (2014) estimate the effect of high-performing mentors on promotion of junior officers.

\section{Data}

Admission to West Point is largely determined by the Whole Candidate Score (WCS) which is a comprehensive measure of entering capabilities. The WCS is a weighted composite score that incorporates high school academic performance, high school rank, SAT scores, leadership potential, and physical fitness. In particular, 60 percent of the WCS is based on the college entrance examination rank (CEER). The CEER score factors in SAT or ACT scores as well as the high school rank convert score (HSRCS), which accounts for differences in high school quality. The remaining 40 percent of the WCS is computed based on the three leadership scores and one physical fitness score, determined by USMA, each accounting for 10 percent of the WCS. The four measures are the following: (1) the faculty appraisal score (FAS); (2) the athletic activities score (AAS); (3) the extracurricular activities score (EAS); and (4) the candidate fitness assessment (CFA). The community leader score (CLS) score is the sum of the first three of the preceding. We observe all these skill measures.

In addition, we observe a variety of student characteristics such as prior-service, attendance at USMAPS, father's and mother's education, as well as the cohort and state of residence of the student. For expositional convenience, we refer to these prior student char-

\footnotetext{
${ }^{9}$ As we have alluded to and is obvious, it is intuitive that the persistence to graduation at West Point relative to persistence to graduation in STEM at most other universities would be higher because cadets cannot switch to a major that might be easier to complete. It is of interest to research more generally whether a variety of majors (and ease of switching) reduces very significantly STEM degree persistence.
} 
acteristics as demographics with the understanding that race and gender are not encompassed by this shorthand. The USMAPS primarily serves students who are recruited as athletes and students with prior Army service. We, therefore, also examine interactions between these variables. Note that there is no separate application for USMAPS. Admission officers may choose to offer USMAPS to potential West Point cadets who lack the grades or skills necessary for immediate admission to West Point.

There are several outcomes of interest including college attainment and the subsequent career outcomes in the Army. We observe whether the student: a) graduated from USMA, b) obtained a commission in the U.S. Army as an officer, c) was retained beyond 5 and 8 years of service, and d) was promoted "below the zone" to major.10 Graduates have a five year obligation and can reenlist for (initially) three years with mutual consent. Below the zone promotion is the expression used to denote early promotion (see the previous footnote). We study each outcome separately below.

We also observe several achievement measures for those cadets that graduate from West Point. The most important measure at graduation is rank on the Order of Merit List (OML) which is a comprehensive measure formed as a weighted average of measures of academic accomplishments, physical capabilities, and leadership potential, supplemented by judgment of relative merit by a board of Army officers. The OML ranks graduating students from best, a rank of one, to worst. The OML is not only prestigious, but also establishes the order in which candidates choose among the 16 military branches, and hence determines which candidates obtain the limited positions available in the most highly sought after branches. We also observe the cumulative GPAs for the three main skill domains, academic, military leadership, and physical skills, as well as in each core course.

Our sample consists of the 11 cohorts of cadets that enrolled at West Point between 1998 and 2008. The sample size of all enrolled cadets is 12,992. The final sample we use for our analysis has a total of 11,503 cadets. This sample has 9,892 white cadets, 840 black cadets,

\footnotetext{
${ }^{10}$ See Appendix B for a summary of promotion procedures in the U.S. military.
} 
and 771 Hispanic cadets, 1,450 white female cadets, 191 black female cadets, and 124 Hispanic female cadets. We have complete records for these 11,503 cadets from their time of entry to up to 16 years following graduation. Cadets not included in our analysis are from racial groups too small in numbers to permit accurate comparisons to matched majority students or cadets with missing data for one or more variables 11

Summary statistics are provided in Table 1 for black, Hispanic and white cadets. This table shows that there are substantial differences in entering test scores by race and ethnicity. The CEER score differences are of particular importance. Recall that the CEER score measures academic preparation and that CEER comprises 60\% of the Whole Candidate Score.

Assessing the effectiveness of West Point training by race and ethnicity requires comparing outcomes of cadets who have comparable skills upon entry. Matching is a particularly promising approach in the West Point setting because there is a large pool of white cadets for matching, and there is overlap of the score distributions. This overlap is portrayed in Figure 1 for black and white cadets. Inspection of these plots reveals that, for each score, the histogram for black candidates falls within the histogram for white cadets $\sqrt{12}$

We also undertake matching analysis to investigate outcomes by gender. For this analysis, we compare outcomes of female white cadets to male white cadets. Table 2 provides a comparison for male and female white cadets.

\section{Empirical Results}

\subsection{Comparison of Black and White Cadets}

We first report our findings that compare black and white cadets. As noted above, we have data for 840 black cadets and 9,892 white cadets. For each black cadet, the matching algorithm searches for a white cadet with closely matched entering credentials. We match

\footnotetext{
${ }^{11}$ Details of sample selection are provided in Appendix A.

${ }^{12}$ Inspection of the upper left panel of Figure 1 reveals that there is an outlier at the lower end of the CEER distribution. We have investigated robustness and find that the results reported below are not sensitive to whether this outlier is included.
} 
cadets based on scores and prior-service measures available to the admissions office of West Point at the time admissions decisions are made. The variables we use for matching are CEER, CLS, PAE, prior active service, attendance at USMAPS, and both prior service and attendance at USMAPS. We, therefore, restrict attention to those variables that are used by West Point for admission decisions. This is not only the most natural starting point from a research perspective, but it is exceedingly important from the perspective of the academy to determine whether there are any systematic differences by race or gender once one controls for the relevant variables that are used in admission.

To assess the quality of the matching algorithm, we begin by comparing the means of the covariates that we use in the matching algorithm for black cadets to the means for the matched white cadets. This comparison is done in columns (1) through (3) of Table 3 using standard difference-in-means test. Column (3) reports the p-values associated with the null hypothesis that the means are the same. It reveals that the means in both subsamples match up quite well for all of the variables used in the analysis.

We next compare the distributions of the three continuous entry score variables for the matched sample. This is done in the left panel of Figure 2. Each graph in Figure 2 is a quantile-quantile plot. For example, the CEER graph for black cadets plots the quantiles of CEER for black cadets (vertical axis) and the matched white cadets (horizontal axis). A perfect match would have all observations lying on a 45-degree line. The graphs for CEER, CLS, and PAE show that the distribution of each of these variables for black cadets is very close to the distribution of the corresponding variable for the matched sample of white cadets 13

Having established that we have a high quality black-white match, we turn to analysis of outcomes, i.e., the second stage of the analysis. Table 4 reports our findings with respect

\footnotetext{
${ }^{13}$ Looking more closely, we see that the upper-left graph in Figure 1 shows that there is one black cadet with a very low CEER score- noticeably below the 45-degree line. The lower-left shows that there is also a black cadet with a CLS score noticeably below the 45-degree line. To investigate robustness, we repeated the analysis without these two observations. We obtained virtually the same results for all of the comparisons reported in the tables below. Not surprisingly, these 2 out of 840 observations have negligible effect on our findings.
} 
to four binary outcome variables: graduation, retention in the Army after 5 years from graduation, retention after 8 years, and early promotion to the rank of Major. These are important outcome measures for West Point. The top panel, labeled "Black-White", reports results of four regressions for our matched sample of black and white cadets. In each of these regressions, the dependent variable is an outcome variable, and the independent variable is an indicator equal to 1 if the cadet is black and 0 if white. Hence, for each regression, the intercept is the mean of the dependent variable for white cadets, and the coefficient of black is the difference in the means of the dependent variable between black and white cadets. We also report heteroskedasticity-robust standard errors.

From the regression in the Column entitled "Graduation", we see that the estimated graduation rate for white cadets is $77.7 \%$ while the estimated graduation rate for black cadets is $75.6 \%$. The estimated -2.1 percentage point difference in graduation rates between black cadets and the matched white cadets has a p-value of .327 . Hence, there is not a significant difference in graduation rates.

From the second and third columns in Table 4, we see that the estimated differences in retention rates between black cadets and the matched white sample are all quantitatively small and statistically insignificant. Thus, five-year and eight-year retention rates are comparable for black and matched white cadets; just under $60 \%$ are retained for 5 years and roughly one third are retained for eight years. Rates of early promotion to major are also comparable at approximately $2.5 \%$ as shown in the last column of Table 4 .

In Table 5 we investigate the entering characteristics of students who graduate. In particular, we investigate the extent to which entering characteristics of those who graduate differ between black and white cadets. Recall that, as shown in Table 3 , the matching algorithm selected matched white cadets with mean entering scores that are virtually the same as the mean entering scores of black cadets. We saw in Table 4 that there is not a significant difference in graduation rates between black and white cadets in the matched sample. Of course, this does not imply that the characteristics of dropouts is the same for black and 
white cadets. It does imply, however, that we can compare mean entering scores of graduates in the matched sample without the need to be concerned about differences in the proportion who remain through graduation.

The top panel of Table 5 investigates the entering scores of black and white cadets who graduated. The differences for CLS and PAE are far from significant at conventional levels, but the difference in CEER scores is significant at the $6 \%$ level. Given that the average entering scores of black and white cadets are equal in the matched sample, the difference in graduating CEER scores suggests that black cadets with high CEER scores are somewhat more likely to leave before graduating than white cadets with high CEER scores. Nevertheless, we conclude that the differences due to attrition are relatively small.

Thus far, we have compared outcomes for the matched black-white sample of admitted cadets. The results reported in Table 5 suggest that we can also compare outcomes for the subset of these matched cadets who graduated. We, therefore, continue our analysis by focusing on differences in achievement among the graduating cadets for which we can measure achievement. The empirical findings are summarized in Table 6 .

Our first measure of achievement is the position on the Order of Merit List which is basically a comprehensive ranking of all graduating cadets. Table 6 shows that the estimated difference in graduating OML rank between black and white cadets is 84.6 and statistically significant. Recall that lower OML is better. Hence this result tells us that black cadets who graduated had less favorable rankings than the matched white cadets. This difference is quantitatively large, translating to a roughly 9 percentage point difference in OML.

Next we focus on academic, physical and leadership measures. The skills are measured by cumulative grade point averages in the relevant courses at the time of graduation. Table 6 shows that black cadets have significantly lower graduating academic scores, academic scores in core common areas, leadership scores, and physical scores than their matched white counterparts.

In light of the difference in academic performance between black and matched white 
cadets, it is of interest to investigate whether there are differences in variables that are observed by the admission officers at West Point, but are not used in the admission decision. Recall that our matching analysis only matches on variables that are explicitly used by West Point to determine whether an applicant is admitted to the school or not. The most promising variable is parental education. West Point collects detailed information of the mother's and the father's educational background. We can, therefore, analyze whether there are significant differences among black and comparably white applicants along this dimension.

Table 7 reports results for education of fathers and mothers. We see that, relative to fathers of matched white cadets, fathers of black cadets have a 9 percentage point lower college graduation rate and a 5.5 percentage point lower rate of completion of a graduate degree. Instead, fathers or black cadets are more likely to have some college or less. Relative to mothers of matched white cadets, mothers of black cadets have a 9.2 percentage point lower college graduation rate but, interestingly, 4.5 percentage point higher rate of completion of a graduate degree. ${ }^{14}$ Together, these results show a tendency toward lower education levels of fathers of black cadets, and somewhat lower education levels of mothers of black cadets. Also, the finding of comparable graduation rates and early career outcomes for black and white matched cadets that have overcome hardship in experience prior to West Point may provide capability to persist after graduation despite the differences in OML and achievement scores. The results also indicate that it may be desirable for West Point to use a broader set of variables when determining admission to the academy. Without having access to data on the full applicant pool it is, however, difficult to answer this question.

Summarizing, we have shown that there is not a significant difference in graduation rates between black cadets and their matched white counterparts. However, black cadets have significantly lower achievement measured by cumulative GPA scores at graduation and significantly less favorable positions on the order of merit list than comparable white cadets. Despite these differences, career outcomes of black cadets and their white counterparts are

\footnotetext{
${ }^{14}$ The differences in academic achievement may also in part be due the fact that black candidates who left West Point had somewhat higher CEER scores than the matched white cadets who left (See Table 5).
} 
very similar. The differences in 5-year and 8-year retention rates and rates of early promotion to major are quantitatively small and statistically insignificant.

\subsection{Comparisons of Hispanic and White Cadets}

We next turn to the results for Hispanic and white cadets. Since the analysis proceeds along the same lines as above, we just summarize the main findings. From the middle panel of Table 3, we see that the means of the variables for Hispanic and white cadets are virtually identical in the matched sample that we created. The QQ plots for the three continuous variables shown in the middle panel of Figure 2 also indicates that the quality of the match is very good. Hence, we conclude that the matching algorithm works well in this application.

From the regressions labeled "Hispanic-White" in Table 4, we see that the differences in binary outcomes for Hispanic and white cadets are all quantitatively small and statistically insignificant once we control for differences in the key characteristics that are use during the admission process at West Point. Hence, we conclude that rates of graduation, retention, and early promotion rates are very similar for comparable Hispanic and white cadets.

Table 5 shows that the differences in entering academic and leadership scores of those who graduated are also quantitatively small. We find that only the difference in physical fitness scores is significant. Thus, there is little indication of differential selective attrition between matched Hispanic and white cadets. From the regressions in Table 6, we see that the differences in OML rank and academic, leadership and physical scores are quantitatively small, with none being close to significant except for the leadership measure.

We thus conclude that there are no systematic achievement or attainments gaps between comparable Hispanic and white cadets.

\subsection{Comparisons of Female and Male White Cadets}

Finally, we turn to the results comparing white female and white male cadets. We find that gender gaps show different patterns than racial gaps. The bottom panel of Table 3 shows that 
the means of the key variables used in the matching analysis for female cadets and matched white cadets are quite close. The QQ plots in the right panel of Figure 2 show that the distributions also line up very closely.

Turning to the regression results, we see in Table 4 that there is a significant difference between matched female and male cadets in graduation rates, retention rates for 5 years, and retention rates for 8 years. Female cadets have a 4.7 percentage point lower graduation rate than male cadets, a 9.3 percentage point lower rate of retention after five years, and an 11.5 percentage point lower rate of retention after eight years. There is not a significant difference between female and male cadets in promotion below zone to major.

In Table 5, we investigate whether there is differential attrition by comparing entry scores of female and male graduates. The regressions reveal that the means for female cadets and matched male cadets are nearly identical. The estimated differences for CEER, CLS, PAE are all exceedingly small relative to the means for male cadets (the intercepts in the regressions), and none are anywhere near significant. Hence, the mean values of these three variables for those who graduated are virtually the same for the female cadets and the matched sample of male cadets, indicating no differential selective attrition.

Table 6 compares several achievement measures for female graduates and male graduates in the matched sample. For all the measures, the difference between female and male graduates is negligible in magnitude and statistically insignificant.

Summarizing, graduation measures for female cadets are significantly lower than those for matched male counterparts, as are retention rates after 5 years and after 8 years. On average, the qualifications of female cadets who drop out are similar to those of male cadets who drop out. On all performance measures at graduation, female cadets and male cadets perform equally well. The closeness of the matched attainment assessments to the differences in the means in the full sample suggest that, unlike race, matching is unnecessary to remove potential biases in this application. 


\section{Closing the Gap: The Role of the Preparatory School}

A unique feature of West Point is that applicants who are not quite ready for enrolling in West Point may be offered an opportunity to attend USMAPS for a year to improve their skills and increase their college readiness. The USMAPS primarily serves minority students, recruited athletes, and students with prior Army service. Students that enroll in the school take a ten-month long preparatory program that is tailored to the individual needs of each student. One key advantage for our analysis is that we observe test scores of students before and after they attend USMAPS.

Our main empirical focus is on the three skills that determine admission to West Point, academic test scores, leadership scores, and physical fitness. Our sample consists of data for students who attended USMAPS and subsequently enrolled in West Point. Note that our sample does not contain all students who attended USMAPS, but only those who were offered and accepted admission to West Point after completing USMAPS. Nonetheless, it is of much interest to investigate the change in performance of these students. Approximately, 240 students are enrolled annually in USMAPS. We have CEER scores for 1,590 students at the point of entry to USMAPS and their CEER scores when they reapplied to West Point. Hence, our sample of CEER observations contains approximately $60 \%$ of students who attended USMAPS over the 11 cohorts we study. For leadership and fitness we have scores for approximately $55 \%$ of USMAPS attendees.

Table 8 shows the sample means and standard deviations for three skill measures that are observed before entering the USMAPS and after graduating from the school.

Table 8 suggests that for our selected sample, USMAPS significantly improved academic readiness. Mean SAT scores improved from 1100 to 1164, which is quite a large and significant gain. USMAPS had smaller effects on the average leadership scores and no significant effect on average physical scores.

Table 9 contains the results from regressions analyzing changes in three different performance measures for students who attended USMAPS. These regressions estimate changes 
in academic, leadership, and physical fitness by race/ethnicity, with black students as the reference category. All three groups make significant gains in academic scores. Regarding academics, black students gain 28.7 CEER points. This is a large gain, roughly .55 standard deviations of CEER scores of black students entering West Point. The other two groups make significantly larger gains than black students, with white students having the largest gains. All three groups also make large, significant gains in leadership scores. Black students gain 23.9 LPS points, .42 standard deviations of leadership scores of black students entering West Point. White students gain significantly more in leadership scores than black students. Hispanic students have somewhat higher gains than black students, but not significantly higher. Black students make small estimated gains in physical fitness that are not statistically significant. By contrast, the other two groups have declines in fitness during their time in USMAPS though only the decline for Hispanic students, 17.177 PAE points, is statistically significant. The latter is substantial, approximately .25 standard deviations of PAE scores of Hispanic students entering West Point. One can speculate that students are spending relatively more time studying than in the gym.

In results not reported (available on request), we extended these regressions to include interactions with gender. We find a small insignificant difference in gains in CEER between male and female black students. Hispanic males have a significantly higher gain in CEER than Hispanic females during attendance at USMAPS. White male students have a gain relative to white female students that is not significant at the $5 \%$ level, but it is significant at the $10 \%$ level. There are small insignificant male-female differences for all three race/ethnicity groups for leadership. Similarly, we find small insignificant male-female differences for all the three groups for changes in physical fitness during attendance at USMAPS.

We have analyzed changes in scores for students who applied to West Point, were offered and accepted admission to USMAPS, and then subsequently reapplied to West Point and were admitted. We conclude that USMAPS is effective in improving academic and leadership skills. USMAPS was not effective in improving fitness scores. For Hispanic and white students, 
fitness scores declined significantly. To put this latter finding in perspective, recall that admission to West Point places $60 \%$ weight on CEER, $30 \%$ on leadership, and $10 \%$ on fitness.

\section{Conclusions}

There are large initial differences in college readiness among enrolling cadets at West Point. In particular, minority students have, on average, significantly lower academic and leadership scores than majority students. Of course, the same is true for most selective colleges and universities in the US. For many institutions, this heterogeneity in preparedness poses an almost insurmountable challenge for evaluating gains from attending the college by race or gender. The difficulty arises for several reasons, the most salient of which are lack of outcome measures adequate to make meaningful comparisons across graduates, and lack of sample sizes for minority students adequate to obtain precise estimates of differences between white and minority students.

By these and other criteria discussed in the paper, we have a data set exceptionally well suited to comparing treatment effects of college attendance by race and also by gender. Utilizing these data, we obtain exceptionally good matches for black-white and Hispanicwhite comparisons, and also for male-female comparisons for white students. We see this exceptional match quality with large samples and comprehensive measures of capabilities as a key contribution of our work. These large, well-balanced samples in turn permit precise comparisons of treatment effects of college attendance by race, ethnicity, and gender.

We find small, insignificant differences in graduation rates between black and white students and between Hispanic and white students. For retention and early promotion to major, we find similarly small and insignificant black-white and Hispanic-white differences. In contrast, there are substantial gender gaps. Graduation rates of white males are approximately five percentage points higher than for white females. The male-female difference in retention rates is larger still. While the differences in graduation rates by race and gender are cause for concern, it bears emphasis that graduation rates at West Point are markedly higher than 
at other selective four-year institutions. Moreover, these high graduation rates are achieved with four years of attendance at the college.

We also studied achievement among the subsample of cadets who graduate from West Point. Our analysis finds that there are significant black-white achievement gaps in the college. This finding holds for broad measures of academic achievement including position on the order of merit list, graduating GPA, and GPA in core courses. These findings contrast with the findings on attainment, retention in the military following graduation, and early promotion to the rank of Major. While attrition rates do not differ between black students and their matched white counterparts, black students who leave have, on average, higher entering CEER scores than white students who leave. This accounts for part of the blackwhite achievement gap at graduation. We find no Hispanic-white or male-female achievement gaps.

As we noted at the outset, a fundamental challenge for West Point and other colleges and universities is increasing the number of minority graduates. This in turn requires attracting more minority applicants and taking measures to compensate for the difference in preparation between minority and majority students. Our analysis of the preparatory school demonstrates the effectiveness of the additional year of education with a curriculum designed to enhance capabilities required for admission to West Point. Selective colleges and universities can potentially benefit from the experiences of USMAPS since they face similar challenges in attracting low-income and minority students who are often not sufficiently well-prepared for the academic rigors of advanced undergraduate education. It is not clear whether highly selective colleges can close these preexisting gaps without offering a more structured and personalized preparatory learning experience that is similar to the one provided by USMAPS. Here, West Point has the advantage that attendance at West Point and USMAPS is tuition free.

A broader implication of this work goes beyond the educational topics that we discussed in this paper. It is intuitive that the U.S. Army should have an officer corps that reflects 
the underlying population of America or the enlisted force to be most effective, achieve its objectives, and promote its legitimacy. These goals are harder to attain if there are significant and unattended achievement gaps within certain groups.

In our analysis, we have emphasized the value of a large sample size and comprehensive measures of students' entry qualifications and their subsequent performance. It is of much interest to consider what would be required if a selective civilian college wished to undertake an assessment of outcomes of its students by race and ethnicity. Colleges currently obtain performance metrics upon student entry (e.g., SAT verbal and math) that permit comparisons across students by race and ethnicity. Colleges know whether students graduate, so they know attainment. They also know GPA for students who graduate, though there is a potential issue of lack of uniformity of grading standards across majors. What most colleges lack is systematic information about performance after graduation (e.g., earnings, attending graduate school). Obtaining such information for all graduates could well be a daunting and costly undertaking. Hence, it is very important to recognize that, for evaluating racial gaps, it is not necessary to gather information for all graduates. Consider assessing the blackwhite gap. With data obtained at the time students enter the college (e.g., SAT verbal and math), matching can be used to determine which entering white students are matched to the entering black students. Then a survey of graduates would only require information about black students and their matched white counterparts. Given the relatively low representation of minority students in most selective colleges, this would appear to be a manageable undertaking. Of course, information for multiple cohorts would likely be needed. 


\section{References}

Abadie, A. and G. Imbens (2006). "Large Sample Properties of Matching Estimators for Average Treatment Effects." Econometrica, 74(1), 235-267.

Anderson, E. and Kim, D., "Increasing the Success of Minority Students in Science and Technology," American Council on Education," March 2016.

Arcidiacono, P., Aucejo, E. and Hotz, V. J., "University Differences in the Graduation of Minorities in STEM Fields: Evidence from California," American Economic Review, Vol. 106(3), 2016, 525-562.

Arcidiacono, P. and Lovenheim, M., "Affirmative Action and the Quality-Fit Trade Off," Journal of Economic Literature, Vol. 54(1), March 2016, 3 - 51.

Bagde, S., Epple, D. and L. Taylor (2016). "Does Affirmative Action Work? Caste, Gender, College Quality, and Academic Success in India," American Economic Review, 106(6): 14951521.

Bertrand, Marianne, Goldin, Claudia, and Katz, Lawrence, "Dynamics of the Gender Gap for Young Professionals in the Financial and Corporate Sectors," American Economic Journal: Applied Economics, Vol. 2, July 2010, 228-255.

Bettinger, Eric and Bridget Long, "Do Faculty Serve as Role Models? The Impact of Instructor Gender on Female Students," The American Economic Review, Vol 95(2), May 2005, 152-157.

Black, Dan, Haviland, Amelia, Sanders, Seth, and Taylor, Lowell, "Why Do Minority Men 
Earn Less? A Study of Wage Differentials among the Highly Educated," The Review of Economics and Statistics, Vol. 88 (2), May 2006, 300-313.

Black, Dan, Haviland, Amelia, Sanders, Seth, and Taylor, Lowell, "Gender Disparities among the Highly Educated," Journal of Human Resources, Vol. 43 (3), Summer 2008, 630-659.

Boozer, M., Krueger, A. and S. Wolkon (1992). "Race and School Quality since Brown v. Board of Education," Brookings Papers on Economic Activity-Microeconomics, 269-326.

Card, D., and A. Krueger (1992). "School Quality and Black-White Relative Earnings: A Direct Assessment," Quarterly Journal of Economics, 107 (1), 151-200.

Carrell, Scott, Marianne Page, and James West, "Sex and Science: How Professor Gender Perpetuates the Gender Gap," The Quarterly Journal of Economics, Vol. 125(3), August 2010, $1101-1144$.

Cestau, D., Epple, D. and H. Sieg (2017). "Admitting Students to Selective Education Programs: Merit, Profiling, and Affirmative Action," Journal of Political Economy, forthcoming.

Chay, K., Guryan, J., and B. Mazumder, "Birth Cohort and the Black-White Achievement Gap: The Roles of Access and Health Soon after Birth," NBER working paper 15078 (2009).

Colarusso, M., Heckel, D., Lyle, D. and W. Skimmyhorn (2016). "Starting Strong: TalentBased Branching of Newly Commissioned U.S. Army Officers." Officer Corps Strategy Monograph Series, Volume 9. U.S. Army War College Press. 
Cook, Michael D., and William N. Evans (2000). "Families or Schools? Explaining the Convergence in White and Black Academic Performance," Journal of Labor Economics 18, 729-754.

Dale, Stacy and Alan Krueger, "Estimating the Payoff to Attending a More Selective College: An Application of Selection on Observables and Unobservables," Quarterly Journal of Economics, Vol. 117 (4), 2002, 1491-1527.

Dale, Stacy and Alan Krueger, "Estimating the Effects of College Characteristics over the Career Using Administrative Earnings Data," Journal of Human Resources, Vol. 49(2), 2014, 323-358.

Fisher, R. A. (1935). Design of Experiments, New York: Hafner.

Fryer, Roland and Levitt, Steven, "An Empirical Analysis of the Gender Gap in Mathematics," American Economic Journal: Applied Economics, Vol. 2 (2), April 2010, 210 -240.

Griffith, Amanda, "Persistence of Women and Minorities in STEM Field Majors: Is it the School that Matters?" Economics of Education Review, Vol. 29, 2010, 911-922.

Gu, X.S. and P. R. Rosenbaum (1993). "Comparison of multivariate matching methods: Structures, distances, and algorithms." Computational and Graphical Statistics, 2, 405-420.

Heckman, J., H. Ichimura, J. Smith and P. Todd (1998). "Characterizing Selection Bias using Experimental Data." Econometrica, 66 (2), 315-331.

Heckman, James, Hidehiko Ichimura and Petra Todd (1997). "Matching As An Econo- 
metric Evaluation Estimator," Review of Economic Studies, 65(2), 261-294.

Ho D, Imai K, King G, Stuart E (2007). "Matching as Nonparametric Preprocessing for Reducing Model Dependence in Parametric Causal Inference." Political Analysis, 15(3), 199236.

Ho D, Imai K, King G, Stuart E (2011). "MatchIt: Nonparametric Preprocessing for Parametric Causal Inference.” Journal of Statistical Software, Volume 42, Issue 8.

Imbens, Guido W., "Matching Methods in Practice: Three Examples," J. Human Resources Spring 2015 vol. 50 no. 2 373-419.

Jaynes, G. and R. Williams (1989). "A Common Destiny: Blacks and American Society," Washington, DC: National Academy Press.

Lyle, D. (2007). "Estimating and Interpreting Peer and Role Model Effects from Randomly Assigned Social Groups at West Point." Review of Economic \& Statistics, 1-20.

Lyle, D. (2009). "The Effects of Peer Group Heterogeneity on the Production of Human Capital at West Point," American Economic Journal: Applied Economics, 1:4, 69-84.

Lyle, D. and J. Smith (2014). "The Effect of High-Performing Mentors on Junior Officer Promotion in the U.S. Army," Journal of Labor Economics, 32, 2, pp. 229-58.

Maddi, S. R., M. D. Matthews, D.R. Kelly, B. Villarreal, B., and M. White, M. (2012). "The role of hardiness and grit in predicting performance and retention of West Point cadets." Military Psychology, 24(1), 19-28. 
Murnane, Richard J., "U.S. High School Graduation Rates: Patterns and Explanations," Journal of Economic Literature, Vol. 51(2), June 2013, 370-422.

Murnane, Richard J. and Hoffman, Stephen, "Graduations on the Rise," Education Next, Fall 2013.

Neal, D. (2006). "Why Has Black-White Skill Convergence Stopped?" in: E. Hanushek and F. Welch, eds., Handbook of the Economics of Education, vol. 1. Oxford: Elsevier North-Holland.

Neal, D. and Johnson, W.R., "The Role of Pre-Market Factors in Black-White Wage Differences," Journal of Political Economy, Vol. 104, 1996, 869-895.

Neal, D. and A. Rick (2014). "The Prison Boom and the Lack of Progress after Smith and Welsh." NBER Working Paper 20283.

Rajeev H. Dehejia and Sadek Wahba (1999). "Causal Effects in Non-experimental Studies: Reevaluating the Evaluation of Training Programs," Journal of the American Statistical Association, 94:448, 1053-1062.

Rajeev H. Dehejia and Sadek Wahba (2002). "Propensity Score-Matching Methods for Nonexperimental Causal Studies," Review of Economics and Statistics, February 2002, 84 (1), $151-61$.

Rosenbaum, Paul and Donald Rubin (1983). "The Central Role of the Propensity Score in Observational Studies for Causal Effects," Biometrika, 70,41-55. 
Rubin, D. (1973). "Matching to Remove Bias in Observational Studies". Biometrics. 29 (1): 159-183.

Rubin, D. (1974). "Estimating Causal Effects of Treatments in Randomized and Non- Randomized Studies," Journal of Educational Psychology, 66 (5), 688-701.

Smith, J. P., and F. R. Welch (1989). "Black Economic Progress After Myrdal," Journal of Economic Literature, 27(2), 519-564.

Thompson, O. (2018), "The Determinants of Racial Differences in Parenting Practices," Journal of Political Economy 126, 438-449. 


\section{A Sample Selection}

Our data set is comprised of the records of all cadets who entered the USMA in years 1998 through 2010. We dropped observations for the following reasons.

- 166 graduated but missing a score: These are largely for cadets who took leaves of absence for religious missions, primarily Mormon missions. This delayed their graduation date. We dropped these observations because the educational experience of these cadets is different from that of the cadets with continuous attendance.

- 156 coded as not having graduated but as having a graduate OML ranking: These are cadets who had taken classes in their fourth year but did not graduate due to being dismissed from the academy (honor, discipline, or grades) or being unable to graduate due to medical reasons in their last year. Of these, 27 remained in the Army because they transferred to another school and were commissioned through ROTC. Again, because some did not graduate and others have a different educational experience, we do not include them in our analysis.

- One cadet is coded with PAE $\geq 900$ (a coding error), and eight others had missing PAE. Hence, they were dropped due to incomplete data.

- 128 coded as not having graduated but have service records: These are cadets who left USMA prior to their 4th year and then joined the Army either through OCS or ROTC. We dropped these observations because the educational experience of these cadets is different from that of the cadets who completed their education at West Point.

- 37 Dropped for grad-clyr $>2008$. We do not have the graduating OML rankings for these cadets.

Our sample includes some cadets who graduated late. The number of such cadets is quite small, roughly $1.25 \%$ of the sample. Our findings are virtually the same if we limit the sample to on-time graduates. 


\section{B A Brief Summary of Promotion Procedures in the U.S. Military}

The US Army uses an up-or-out promotion system 15. Officers passed over twice by promotion boards are required to be discharged from the Army. The first important promotion is the one from captain to major, which happens after approximately the 10 years of service. Promotions to lower grades are virtually automatic.

Eligible officers must be recommended by their commanders to be considered for promotion. Officers considered for promotion are divided into three zones of consideration: in-thezone (IZ), below-the-zone (BZ), if they are recommended for promotion one year before being eligible for IZ consideration, and above-the-zone (AZ), if they are considered for promotion one or more years after being eligible for IZ consideration. These categories roughly correspond to early promotions, timely promotions, and late promotions. The below-the-zone consideration is a key mechanism to identify and boost the careers of exceptionally skilled officers who have the potential to become battalion and brigade commanders. Most promotions take place in-the-zone, however.

We also observe early promotion, typically known as below the zone selection, to major. We code these outcomes as zero if an officer either went before the board and was turned down or did not go in front of the board. The outcome is 1 if the officer received the promotion. Note that the fraction of early promotion is small in both samples.

Commissioned officers compete for promotions only against officers in their same competitive category. Before March 26, 2009, the Army competitive category included all combat and combat support branches and some combat service support branches. The Army Regulation 600-3 of 2009 divided the Army competitive category into three competitive categories, which correspond to the three functional categories of the Army: Operations or Maneuver, Fires and Effects, Operations Support, and Force Sustainment. Operations include all com-

\footnotetext{
${ }^{15}$ The up-or-out rules will be relaxed in the upcoming years
} 
bat branches and a few combat support branches. Operations Support includes all remaining combat support branches and functional areas ${ }^{16}$ Force Sustainment includes all combat service support branches that are not special branches of the Army. Each special branch makes up a different competitive category. It is important to note that by federal law 17 , and by the rules of the Department of Defense ${ }^{18}$, officers in each competitive category must have similar promotion opportunities in a five-year horizon. Except for the promotions to major of the 1998 and 1999 cohorts and the BZ of the 2000 cohort, all other observations fall into the current system. Considered officers are evaluated by centralized promotion boards. There are around 90 centralized selection boards a year. Board members evaluate all officers in the Operations, Operations Support, and Force Sustainment competitive categories regardless of the considered officer's or the board member's branch. However, each competitive category is voted separately. The board receives a memorandum of instructions that provides guidance on the selection process, including the recommended selection number, the maximum number, maximum BZ opportunity, and specific branch priorities if any 19

\section{Tables and Figures}

\footnotetext{
${ }^{16}$ A grouping of officers, other than branches, with related tasks and similar skills and training. Functional areas are assigned during the sixth year of service.

${ }^{17} 10$ U.S. Code 623

${ }^{18}$ DODI 1320.12 and DODI 1320.13

${ }^{19}$ The selection process has three phases. First, the board produces an order of merit list (OML) of all the In and Above-the-Zone candidates (I/AZ). Second, it generates an OML of potential BZ selects. In the third phase, it compares BZ candidates to I/AZ candidates, and determines the BZ candidates that are clearly superior to all I/AZ candidates replaced by them in the promotion list.
} 
Table 1: Descriptive Statistics by Race: Full Sample

\begin{tabular}{|c|c|c|c|}
\hline & Variable & mean & std dev \\
\hline \multirow{11}{*}{ Black } & ceer & 551 & 52 \\
\hline & cls & 611 & 54 \\
\hline & pae & 574 & 81 \\
\hline & male & 0.766 & 0.423 \\
\hline & usmaps & 0.419 & 0.493 \\
\hline & prior service & 0.057 & 0.232 \\
\hline & maps \& prior service & 0.052 & 0.222 \\
\hline & graduate & 0.785 & 0.410 \\
\hline & retain 60 & 0.602 & 0.489 \\
\hline & retain 96 & 0.357 & 0.479 \\
\hline & promote major & 0.026 & 0.159 \\
\hline \multirow{11}{*}{ Hispanic } & ceer & 585 & 54 \\
\hline & cls & 602 & 52 \\
\hline & pae & 537 & 68 \\
\hline & male & 0.839 & 0.367 \\
\hline & usmaps & 0.263 & 0.440 \\
\hline & prior service & 0.088 & 0.283 \\
\hline & usmaps \& prior service & 0.071 & 0.257 \\
\hline & graduate & 0.763 & 0.425 \\
\hline & retain 60 & 0.633 & 0.482 \\
\hline & retain 96 & 0.372 & 0.483 \\
\hline & promote major & 0.025 & 0.155 \\
\hline \multirow{11}{*}{ White } & ceer & 607 & 58 \\
\hline & cls & 620 & 51 \\
\hline & pae & 552 & 71 \\
\hline & male & 0.853 & 0.353 \\
\hline & usmaps & 0.111 & 0.315 \\
\hline & prior service & 0.068 & 0.252 \\
\hline & usmaps \& prior service & 0.052 & 0.223 \\
\hline & graduate & 0.809 & 0.393 \\
\hline & retain 60 & 0.627 & 0.483 \\
\hline & retain 96 & 0.378 & 0.485 \\
\hline & promote major & 0.037 & 0.188 \\
\hline
\end{tabular}


Table 2: Descriptive Statistics by Gender: Full Sample

\begin{tabular}{llcc}
\hline & Variable & mean & std dev \\
\hline & ceer & 612 & 58 \\
& cls & 628 & 46 \\
White & pae & 555 & 70 \\
Female & prmaps & 0.091 & 0.288 \\
& usmaps \& price & 0.031 & 0.172 \\
& graduate & 0.023 & 0.150 \\
& retain 60 & 0.764 & 0.424 \\
& retain 96 & 0.544 & 0.498 \\
& promote major & 0.278 & 0.448 \\
& ceer & 0.033 & 0.178 \\
\hline \multirow{4}{*}{ White } & cls & 606 & 58 \\
Male & usmaps & 623 & 50 \\
& prior service & 551 & 71 \\
& usmaps \& prior service & 0.057 & 0.259 \\
& graduate & 0.816 & 0.387 \\
& retain 60 & 0.641 & 0.479 \\
& retain 96 & 0.395 & 0.489 \\
& promote major & 0.037 & 0.189 \\
\hline
\end{tabular}


Table 3: Difference-in-Means Balance Tests: Matched Sample

\begin{tabular}{llccc}
\hline & Variable & Treatment & Control & Difference \\
\hline & ceer & 0.5510 & 0.5508 & 0.0003 \\
& pae & 0.5753 & 0.5742 & 0.0011 \\
Black- & cls & 0.6044 & 0.6060 & -0.0016 \\
White & male & 0.7726 & 0.7750 & -0.0024 \\
& usmaps & 0.4167 & 0.4179 & -0.0012 \\
& prior service & 0.0679 & 0.0619 & 0.0060 \\
& usmaps \& prior & 0.0536 & 0.0536 & 0.0000 \\
\hline & ceer & 0.5852 & 0.5852 & 0.0000 \\
& pae & 0.5373 & 0.5373 & 0.0000 \\
Hispanic- & cls & 0.6022 & 0.6022 & 0.0000 \\
White & male & 0.8392 & 0.8392 & 0.0000 \\
& usmaps & 0.2633 & 0.2633 & 0.0000 \\
& prior service & 0.0882 & 0.0882 & 0.0000 \\
& usmaps \& prior & 0.0713 & 0.0713 & 0.0000 \\
\hline & ceer & 0.6120 & 0.6118 & 0.0001 \\
Male- & pae & 0.5547 & 0.5550 & -0.0004 \\
Female & usmaps & 0.6238 & 0.6238 & 0.0000 \\
(White) & prior service & 0.0924 & 0.0924 & 0.0000 \\
& usmaps \& prior & 0.0290 & 0.0290 & 0.0000 \\
& & 0.0214 & 0.0000 \\
\hline
\end{tabular}


Table 4: Attainment and Career Outcomes

\begin{tabular}{|c|c|c|c|c|c|}
\hline & & Graduation & $\begin{array}{c}\text { Retention } \\
\text { after } 60 \text { Months }\end{array}$ & $\begin{array}{c}\text { Retention } \\
\text { after } 96 \text { Months }\end{array}$ & $\begin{array}{l}\text { Early Promotion } \\
\text { to Major }\end{array}$ \\
\hline \multirow{5}{*}{$\begin{array}{l}\text { Black- } \\
\text { White }\end{array}$} & \multirow[t]{2}{*}{ black } & -0.021 & -0.011 & 0.019 & -0.002 \\
\hline & & $(0.022)$ & $(0.025)$ & $(0.024)$ & $(0.008)$ \\
\hline & \multirow[t]{2}{*}{ intercept } & 0.777 & 0.590 & 0.330 & 0.027 \\
\hline & & $(0.016)$ & $(0.019)$ & $(0.018)$ & $(0.006)$ \\
\hline & $\mathrm{N}$ & 1,540 & 1,540 & 1,540 & 1,540 \\
\hline \multirow{5}{*}{$\begin{array}{l}\text { Hispanic- } \\
\text { White }\end{array}$} & \multirow[t]{2}{*}{ hispanic } & -0.023 & 0.005 & -0.015 & -0.011 \\
\hline & & $(0.022)$ & $(0.025)$ & $(0.025)$ & $(0.009)$ \\
\hline & \multirow[t]{2}{*}{ intercept } & 0.779 & 0.621 & 0.387 & 0.036 \\
\hline & & $(0.016)$ & $(0.018)$ & $(0.018)$ & $(0.007)$ \\
\hline & $\mathrm{N}$ & 1,476 & 1,476 & 1,476 & 1,476 \\
\hline \multirow{5}{*}{$\begin{array}{l}\text { Male- } \\
\text { Female } \\
\text { (White) }\end{array}$} & \multirow[t]{2}{*}{ female } & -0.047 & -0.093 & -0.115 & -0.009 \\
\hline & & $(0.016)$ & $(0.019)$ & $(0.018)$ & $(0.007)$ \\
\hline & \multirow[t]{2}{*}{ intercept } & 0.815 & 0.640 & 0.394 & 0.041 \\
\hline & & $(0.011)$ & $(0.013)$ & $(0.014)$ & $(0.006)$ \\
\hline & $\mathrm{N}$ & 2,745 & 2,745 & 2,745 & 2,745 \\
\hline
\end{tabular}


Table 5: Difference-in-Means Balance Tests: Graduating Sample

\begin{tabular}{|c|c|c|c|c|}
\hline & & $\begin{array}{c}\text { Academic } \\
\text { ceer }\end{array}$ & $\begin{array}{c}\text { Leadership } \\
\text { cls }\end{array}$ & $\begin{array}{c}\text { Physical } \\
\text { pae }\end{array}$ \\
\hline \multirow{5}{*}{$\begin{array}{l}\text { Black- } \\
\text { White }\end{array}$} & \multirow[t]{2}{*}{ black } & -5.529 & -1.451 & 6.414 \\
\hline & & $(2.938)$ & $(3.22)$ & $(4.623)$ \\
\hline & \multirow[t]{2}{*}{ intercept } & 560.079 & 607.577 & 569.484 \\
\hline & & $(2.123)$ & $(2.299)$ & $(3.348)$ \\
\hline & $\mathrm{N}$ & 1,179 & 1,179 & 1,179 \\
\hline & \multirow[t]{2}{*}{ hispanic } & -0.003 & 0.006 & -0.012 \\
\hline \multirow{4}{*}{$\begin{array}{l}\text { Hispanic- } \\
\text { White }\end{array}$} & & $(0.004)$ & $(0.004)$ & $(0.005)$ \\
\hline & \multirow[t]{2}{*}{ intercept } & 0.589 & 0.605 & 0.541 \\
\hline & & $(0.002)$ & $(0.002)$ & $(0.002)$ \\
\hline & $\mathrm{N}$ & 1,132 & 1,132 & 1,132 \\
\hline \multirow{5}{*}{$\begin{array}{l}\text { Male- } \\
\text { Female } \\
\text { (white) }\end{array}$} & female & 0.000 & 0.000 & -0.002 \\
\hline & \multirow{3}{*}{ intercept } & $(0.003)$ & $(0.002)$ & $(0.003)$ \\
\hline & & 0.614 & 0.624 & 0.557 \\
\hline & & $(0.002)$ & $(0.002)$ & $(0.002)$ \\
\hline & $\mathrm{N}$ & 2,168 & 2,168 & 2,168 \\
\hline
\end{tabular}


Table 6: Achievement Analysis

\begin{tabular}{|c|c|c|c|c|c|c|}
\hline & & OML & Academic & Academic Core & Physical & Leadership \\
\hline \multirow{5}{*}{$\begin{array}{l}\text { Black- } \\
\text { White }\end{array}$} & black & 84.6 & -0.132 & -0.145 & -0.120 & -0.090 \\
\hline & & $(13.7)$ & $(0.023)$ & $(0.024)$ & $(0.022)$ & $(0.021)$ \\
\hline & intercept & 569.5 & 2.752 & 2.621 & 3.052 & 2.997 \\
\hline & & $(10.3)$ & $(0.017)$ & $(0.018)$ & $(0.017)$ & $(0.015)$ \\
\hline & $\mathrm{N}$ & 1,179 & 1,179 & 1,179 & 1,179 & 1,179 \\
\hline \multirow{5}{*}{$\begin{array}{l}\text { Hispanic- } \\
\text { White }\end{array}$} & hispanic & 25.8 & -0.022 & -0.046 & -0.015 & -0.056 \\
\hline & & $(21.2)$ & $(0.035)$ & $(0.038)$ & $(0.033)$ & $(0.029)$ \\
\hline & intercept & 509.8 & 2.881 & 2.751 & 3.019 & 3.026 \\
\hline & & $(8.4)$ & $(0.014)$ & $(0.015)$ & $(0.012)$ & $(0.012)$ \\
\hline & $\mathrm{N}$ & 1,132 & 1,132 & 1,132 & 1,132 & 1,132 \\
\hline \multirow{5}{*}{$\begin{array}{l}\text { Male- } \\
\text { Female } \\
\text { (white) }\end{array}$} & female & -3.00. & -0.001 & -0.013 & 0.01 & 0.018 \\
\hline & & $(11.2)$ & $(0.019)$ & $(0.020)$ & $(0.017)$ & $(0.015)$ \\
\hline & intercept & 428.1 & 3.033 & 2.915 & 3.082 & 3.077 \\
\hline & & $(8.0)$ & $(0.014)$ & $(0.014)$ & $(0.011)$ & $(0.011)$ \\
\hline & $\mathrm{N}$ & 2,168 & 2,168 & 2,168 & 2,168 & 2,168 \\
\hline
\end{tabular}

Standard error are reported in parentheses. 
Table 7: Robustness Checks: Parental Education

\begin{tabular}{|c|c|c|c|c|c|c|c|}
\hline \multicolumn{2}{|c|}{ Black-White: } & Missing & High School & High School & Som & Bachelors & Graduate \\
\hline & black & $\begin{array}{c}0.028 \\
(0.013)\end{array}$ & $\begin{array}{c}0.036 \\
(0.010)\end{array}$ & $\begin{array}{c}0.030 \\
(0.018)\end{array}$ & $\begin{array}{c}0.047 \\
(0.020)\end{array}$ & $\begin{array}{l}-0.091 \\
(0.024)\end{array}$ & $\begin{array}{l}-0.050 \\
(0.023)\end{array}$ \\
\hline $\begin{array}{l}\text { Father } \\
\text { Education }\end{array}$ & intercept & $\begin{array}{c}0.054 \\
(0.009)\end{array}$ & $\begin{array}{c}0.021 \\
(0.006)\end{array}$ & $\begin{array}{c}0.123 \\
(0.012)\end{array}$ & $\begin{array}{c}0.159 \\
(0.014)\end{array}$ & $\begin{array}{c}0.350 \\
(0.018)\end{array}$ & $\begin{array}{c}0.293 \\
(0.017)\end{array}$ \\
\hline & black & $\begin{array}{c}0.028 \\
(0.013)\end{array}$ & $\begin{array}{c}0.012 \\
(0.008)\end{array}$ & $\begin{array}{l}-0.016 \\
(0.018)\end{array}$ & $\begin{array}{c}0.023 \\
(0.022)\end{array}$ & $\begin{array}{l}-0.092 \\
(0.024)\end{array}$ & $\begin{array}{c}0.045 \\
(0.020)\end{array}$ \\
\hline $\begin{array}{l}\text { Mother } \\
\text { Education }\end{array}$ & intercept & $\begin{array}{c}0.054 \\
(0.009)\end{array}$ & $\begin{array}{c}0.021 \\
(0.006)\end{array}$ & $\begin{array}{c}0.147 \\
(0.013)\end{array}$ & $\begin{array}{c}0.224 \\
(0.016)\end{array}$ & $\begin{array}{c}0.386 \\
(0.018)\end{array}$ & $\begin{array}{c}0.167 \\
(0.014)\end{array}$ \\
\hline & $\mathrm{N}$ & 1,540 & 1,540 & 1,540 & 1,540 & 1,540 & 1,540 \\
\hline
\end{tabular}


Table 8: Descriptive Statistics: USMAPS Sample

\begin{tabular}{llcc}
\hline & Variable & mean & std dev \\
\hline & ceer & 550 & 59 \\
& wcs & 5671 & 368 \\
& sat & 1164 & 112 \\
Skills & lagged sat & 1099 & 96 \\
& leadership (cls) & 606 & 53 \\
& lagged leadership (cls) & 583 & 70 \\
& athletic (pae) & 548 & 74 \\
& lagged athletic (pae) & 557 & 86 \\
\hline \multirow{5}{*}{ Demographics } & .191 & .393 \\
& black hispanic & .115 & .319 \\
& athletes & .251 & .433 \\
& prior service & .377 & .485 \\
\hline
\end{tabular}

Table 9: The Effectiveness of the USMAPS

\begin{tabular}{l|ccc}
\hline & $\begin{array}{c}\text { Academic } \\
\text { ceer }\end{array}$ & $\begin{array}{c}\text { Leadership } \\
\text { cls }\end{array}$ & $\begin{array}{c}\text { Physical } \\
\text { pae }\end{array}$ \\
\hline Intercept (Black) & 28.66 & 23.91 & 5.65 \\
& $(1.62)$ & $(2.22)$ & $(3.96)$ \\
\hline Hispanic & 6.88 & 1.22 & -22.83 \\
& $(3.01)$ & $(3.72)$ & $(6.09)$ \\
\hline White & 18.46 & 7.32 & -14.08 \\
& $(2.08)$ & $(2.77)$ & $(4.70)$ \\
\hline $\mathrm{N}$ & 1,590 & 1,423 & 1,431 \\
\hline \multicolumn{4}{l}{ Standard error are reported in parentheses. } \\
\hline
\end{tabular}


Figure 1. Histograms of CEER, PAE and CLS for black and white cadets. Each graph shows the histogram for white cadets overlaid by the histogram for black cadets.
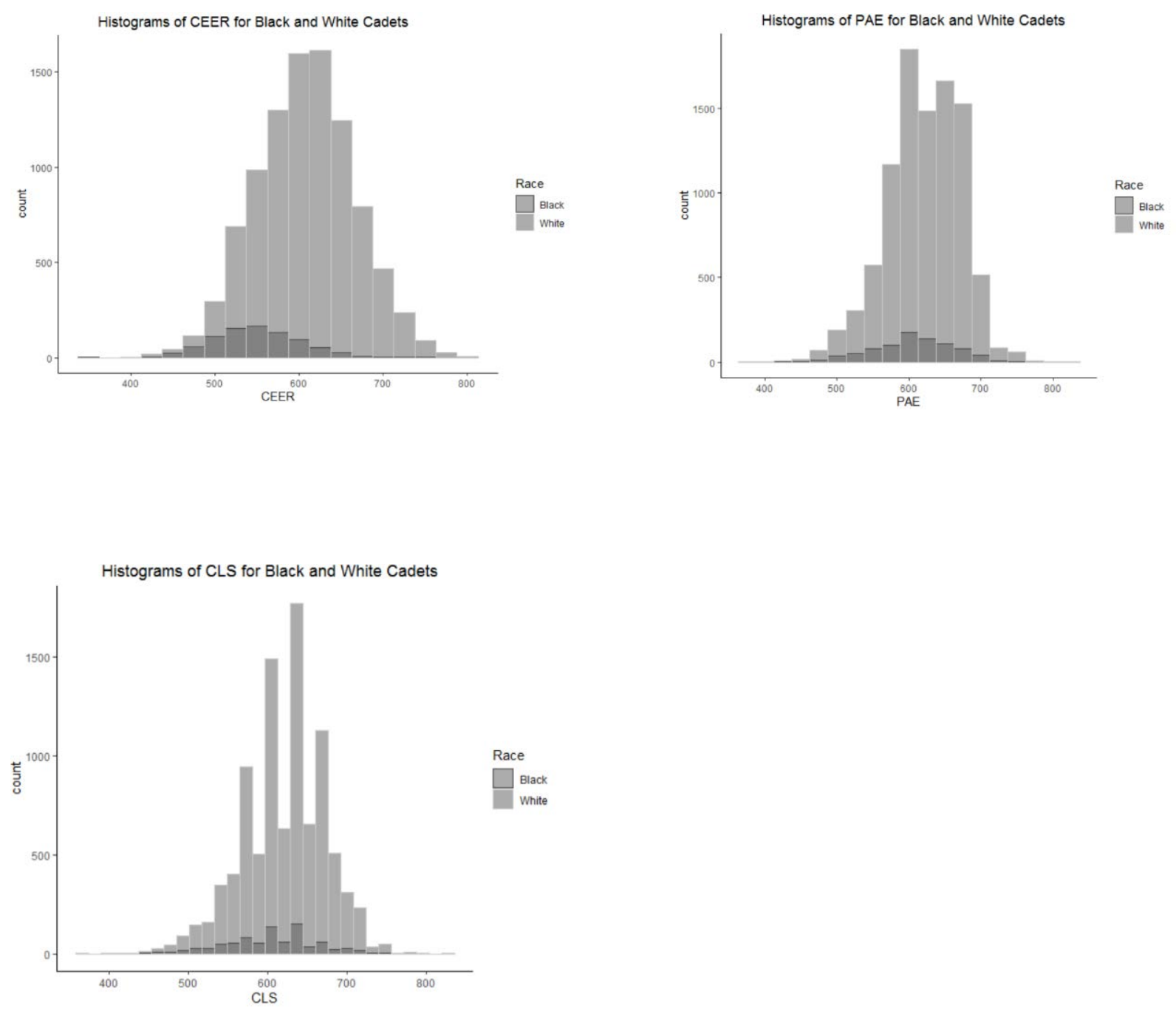
Figure 2: Comparisons of Distributions of Focal (Vertical Axes) and Matched Control Groups

Black

Ceer

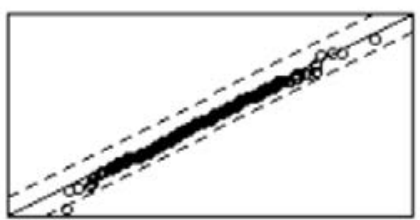

CLS
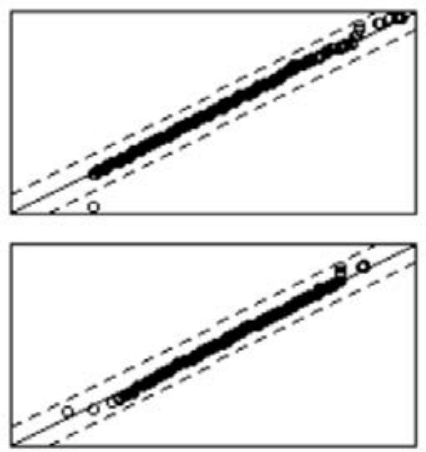

Hispanic
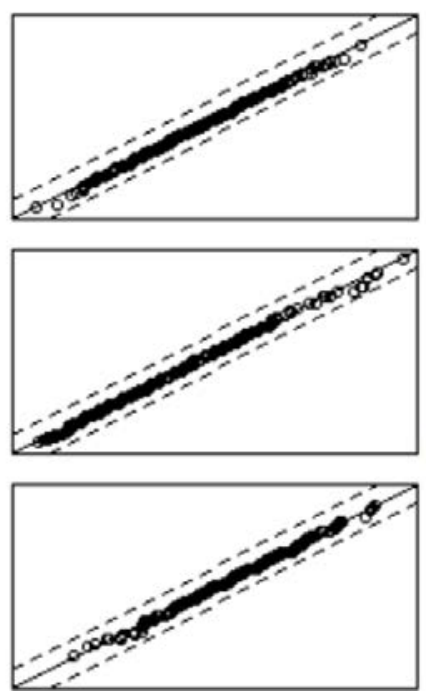

Female
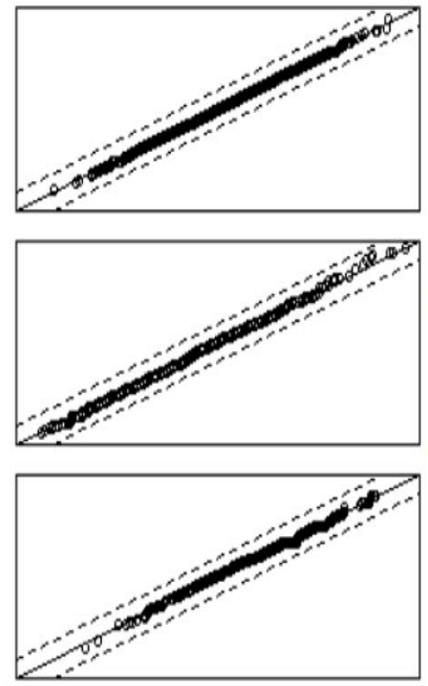